\title{
Outcomes of Infants Undergoing Modified Blalock-Taussig Shunt Procedures in Oman A retrospective study
}

"Samiuddin Shaikh, ${ }^{1}$ Khaloud S. Al-Mukhaini, ${ }^{1}$ Abdul Hakeem Al-Rawahi, ${ }^{2}$ Omer Al-Dafie ${ }^{1}$

\begin{abstract}
Objectives: A modified Blalock-Taussig (mBT) shunt procedure is a common palliative surgery used to treat infants and children with cyanotic congenital heart disease (CCHD). This study aimed to report the outcomes of infants and children undergoing $\mathrm{mBT}$ shunt procedures in Oman. In addition, risk factors associated with early mortality, inter-stage mortality and reintervention were assessed. Methods: This retrospective cohort study was conducted from January 2016 to December 2018 at the National Heart Centre, Muscat, Oman. All paediatric patients with CCHD undergoing $\mathrm{mBT}$ shunt procedures as a primary palliative procedure during this period were included. Data were retrieved from electronic hospital records. Kaplan-Meier survival curves were used to describe overall survival. Results: A total of 50 infants and children were included in this study. The in-hospital mortality and interstage mortality rates were $10 \%$ and $6.7 \%$, respectively. Preoperative mechanical ventilation (odds ratio $[\mathrm{OR}]=3.00$, 95\% confidence interval $[\mathrm{CI}]: 1.98-4.76 ; P=0.007)$ and cardiopulmonary bypass $(\mathrm{OR}=4.09,95 \% \mathrm{CI}: 2.44-6.85 ; P=$ 0.002 ) were significant risk factors for early mortality. In-hospital and interval surgical reintervention rates were $12 \%$ and $13.3 \%$, respectively. Following the primary shunt procedure, the median time to second-stage surgery was 15.5 months (range: 5.0-34.0 months). Conclusion: The findings of this study support those reported in international research regarding the risks associated with $\mathrm{mBT}$ shunt surgeries. In particular, preoperative mechanical ventilation and cardiopulmonary bypass were significant risk factors for early mortality.
\end{abstract}

Keywords: Pediatrics; Congenital Heart Diseases; Cardiovascular Surgical Procedures; Modified Blalock-Taussig Procedure; Patient Outcome Assessment; Hospital Mortality; Risk Factors; Oman.

\section{AdVANCES IN KNOWLedge \\ Outcomes following modified Blalock-Taussig (mBT) shunt procedures vary worldwide. To the best of the authors' knowledge, this is the first study to report outcomes following mBT shunt procedures performed in Oman. \\ This study identifies various risk factors for mortality following this procedure in the local population. \\ These findings provide a baseline for future comparative analysis at both the regional and international level.}

\section{Application to Patient Care}

Knowledge of likely outcomes following mBT shunt procedures in a local setting will be useful to help the parents of infants and children with cyanotic congenital heart disease make informed treatment choices.

Moreover, the findings of this study may result in modifications to clinical practice, thereby improving outcomes. In particular, certain high-risk patient categories warrant extra vigilance, such as those requiring preoperative mechanical ventilation or intraoperative cardiopulmonary bypass.

$\mathrm{I}$ N OMAN, THE INCIDENCE OF CONGENITAL HEART disease is approximately 7.1 per 1,000 live births; of these, $21.7 \%$ are diagnosed with cyanotic congenital heart disease (CCHD). ${ }^{1}$ Many infants with CCHD and inadequate pulmonary blood flow require palliative interventions early in life in order to alleviate severe cyanosis. ${ }^{2}$ These include maintaining the patency of the ductus arteriosus, either by using a cardiac catheter to percutaneously insert a stent or by surgically creating a systemic-to-pulmonary artery shunt. ${ }^{3}$

A modified Blalock-Taussig shunt (mBT) is the most common type of systemic-to-pulmonary artery shunt wherein the ipsilateral innominate or subclavian artery is connected to the pulmonary artery using a prosthetic graft made of polytetrafluoroethylene. ${ }^{3}$ However, despite considerable improvements in congenital heart surgery in recent years, $\mathrm{mBT}$ shunt procedures are still associated with significant morbidity and mortality. ${ }^{4-6}$ For instance, in-hospital mortality rates following $\mathrm{mBT}$ shunt procedures range from 7.3-9.8\%.,5 Moreover, even after discharge, between $5-13.9 \%$ of patients do not survive long enough to undergo the next stage of surgery in the form of a Glenn shunt or total correction procedure. ${ }^{5,6}$

Various risk factors have been identified as resulting in worse outcomes for patients receiving mBT shunts, including the age and weight of the child at the time of surgery, the size of the shunt, pulmonary atresia with intact ventricular septum 
(PAIVS) and preoperative shock or acidosis. ${ }^{5,7-9}$ The immediate postoperative period following insertion of the mBT shunt is when the patient is most vulnerable. According to Petrucci et al., 33\% of deaths in neonates undergoing $\mathrm{mBT}$ shunt procedures occurred within 24 hours of surgery, with $75 \%$ occurring within the first month. ${ }^{10}$ Moreover, the procedure can result in complications such as pulmonary overcirculation (30\%) and shunt failure including shunt thrombosis or stenosis (8-23\%). ${ }^{11,12}$ Risk factors for shunt failure include the use of small shunts or a central shunt, as well as postoperative extracorporeal membrane oxygenation (ECMO) support. ${ }^{11,12}$

To the best of the authors' knowledge, no established data have yet been reported regarding the outcomes of $\mathrm{mBT}$ shunt procedures among paediatric cases in Oman, particularly in terms of morbidity and mortality. As such, this study aimed to determine outcomes of infants with CCHD following $\mathrm{mBT}$ shunt procedures in Oman and evaluate risk factors associated with early mortality, inter-stage mortality and reintervention.

\section{Methods}

This retrospective cohort study was conducted from January 2016 to December 2018 at the National Heart Centre in Muscat, Oman. This centre receives referrals from all over the country for infants and children with congenital heart diseases who require assessment, surgical intervention or cardiac catheterisation. All neonates and infants who underwent $\mathrm{mBT}$ shunt procedures as a primary palliative procedure during the study period were identified using the surgical database. Patients were excluded if they had undergone $\mathrm{mBT}$ shunt surgeries as part of a Norwood procedure-i.e. an aortic arch reconstruction plus atrial septectomy and $\mathrm{mBT}$ shunt or a right ventricleto-pulmonary artery conduit, usually performed in cases of hypoplastic left heart syndrome-or to alleviate hypoxia after pulmonary artery banding.

Information regarding the patients' demographic characteristics, underlying anatomical details, surgical notes, postoperative clinical notes, outpatient followup visits and outcome data were collected from the surgical database and electronic hospital record system. Patients were classified as duct-dependent if they required an infusion of prostaglandins to ensure ductus arteriosus patency and/or if the patent ductus arteriosus was the main source of pulmonary blood flow. All patients were followed-up either until they underwent the next stage of surgery-consisting of either a total correction or stage 2 palliation (i.e. a
Glenn procedure)—or for a minimum of one year after the index procedure (i.e. December 2019).

Data were analysed using the Statistical Package for the Social Sciences (SPSS), Version 22.0 (IBM Corp., Armonk, New York, USA). The outcome variables of interest included early mortality, inter-stage mortality and survival to next stage of surgery. Early mortality was defined as mortality occurring within 30 days of the index operation, while inter-stage mortality (i.e. interval mortality) was defined as mortality occurring between 30 days after the index operation and the next surgical stage. Survival to the second stage of surgery was defined as survival from the initial surgery to the next planned surgical intervention. Categorical variables were presented as frequencies and percentages, while continuous variables were presented as medians and interquartile ranges (IQRs). Kaplan-Meier survival curves were used to describe overall survival. Univariate associations were assessed using a Chi-squared test, along with odds ratios (ORs) and 95\% confidence intervals (CIs) wherever applicable. A $P$ value of $<0.050$ was considered statistically significant.

Ethical approval for this study was obtained through the institutional ethical approval board of the Royal Hospital as well as the Centre of Studies and Research of the Ministry of Health in Oman (SRC\#120/2018 code \#9368). The need for patient consent was waived in view of the retrospective nature of the study.

\section{Results}

A total of 50 paediatric patients with CCHD underwent $\mathrm{mBT}$ shunt procedures as a first palliative surgery during the study period. The primary indication for the procedure was to provide a stable source of pulmonary blood flow sufficient to maintain systemic oxygen saturation $\left(\mathrm{SpO}_{2}\right)$ at $75-85 \%$. The median age at surgery was 22.5 days (IQR: 7.2-90.0 days) and the median weight was $3.2 \mathrm{~kg}$ (IQR: $2.7-4.2 \mathrm{~kg}$ ). Over half of the patients $(\mathrm{n}=26 ; 52 \%)$ were neonates (i.e. $\leq 28$ days old). The underlying diagnosis was either single ventricle $(\mathrm{n}=25 ; 50 \%)$ or biventricular $(\mathrm{n}=$ $25 ; 50 \%)$ defects. A total of 20 patients (40\%) received preoperative mechanical ventilation. Nine patients (18\%) had previously undergone failed attempts at cardiac catheterisation (e.g. ductal stents) prior to the mBT shunt procedure [Table 1].

Among those with single ventricle defects, the majority had PAIVS ( $n=7 ; 28 \%$ ), followed by tricuspid atresia and pulmonary atresia $(n=4 ; 16 \%)$, tricuspid atresia and restrictive ventricular septal defect (VSD; 
Table 1: Baseline characteristics of infants and children with cyanotic congenital heart disease undergoing modified Blalock-Taussig shunt procedures in Oman $(\mathrm{N}=50)$

\begin{tabular}{lc} 
Characteristic & $\mathbf{n}(\%)$ \\
Age in days at time of surgery & \\
$\leq 28$ & $26(52)$ \\
$>28$ & $24(48)$ \\
Median (IQR) & $22.5(7.2-90.0)$ \\
Gender & \\
Male & $27(54)$ \\
Female & $23(46)$ \\
Weight in kg at time of surgery & \\
$<2.5$ & $7(14)$ \\
$\geq 2.5$ & $43(86)$ \\
Median (IQR) & $3.2(2.7-4.2)$ \\
Underlying diagnosis & \\
Single ventricle defect & $25(50)$ \\
Biventricular defect & $25(50)$ \\
Circulation status & \\
Duct-dependent & \\
Non-duct-dependent & $20(40)$ \\
Preoperative mechanical ventilation & $30(60)$ \\
Yes & $20(40)$ \\
No & \\
Preoperative acidosis* & \\
Yes & \\
No & \\
\hline No & \\
\hline
\end{tabular}

$I Q R=$ interquartile range. "Defined by an arterial blood $p H$ value of $<7.3$.

$\mathrm{n}=4 ; 16 \%)$, unbalanced atrioventricular septal defect (AVSD) and hypoplastic right ventricle $(\mathrm{n}=2 ; 8 \%)$, pulmonary atresia and double-inlet left ventricle $(\mathrm{n}=2 ; 8 \%)$, pulmonary atresia with AVSD and total anomalous pulmonary venous connection $(\mathrm{n}=2$; $8 \%)$ and other defects $(n=4 ; 16 \%)$. For those with biventricular defects, the most common underlying diagnosis was pulmonary atresia and VSD ( $\mathrm{n}=10$; $40 \%$ ), followed by tetralogy of Fallot ( $n=7 ; 28 \%$ ), dextro-transposition of the great arteries with VSD and pulmonary stenosis $(\mathrm{n}=3 ; 12 \%)$, AVSD and tetralogy of Fallot $(\mathrm{n}=2 ; 8 \%)$ and other defects $(\mathrm{n}=$ 3; $12 \%)$.
Table 2: Surgical details and outcomes of infants and children with cyanotic congenital heart disease undergoing modified Blalock-Taussig shunt procedures in Oman $(\mathrm{N}=50)$

\begin{tabular}{|c|c|}
\hline Variable & n (\%) \\
\hline \multicolumn{2}{|l|}{ Surgical approach } \\
\hline Sternotomy & $45(90)$ \\
\hline Thoracotomy & $5(10)$ \\
\hline \multicolumn{2}{|l|}{ Cardiopulmonary bypass } \\
\hline Yes & $16(32)$ \\
\hline No & $34(68)$ \\
\hline \multicolumn{2}{|l|}{ Arterial connection } \\
\hline Innominate/subclavian & $35(70)$ \\
\hline Other & $15(30)$ \\
\hline \multicolumn{2}{|l|}{ Other surgical/non-surgical details } \\
\hline Median shunt size in mm (range) & $4(3-5)$ \\
\hline Mean postoperative $\mathrm{SpO}_{2}$ in $\% \pm \mathrm{SD}$ & $82.6 \pm 6.3$ \\
\hline $\begin{array}{l}\text { Median duration of postoperative MV in } \\
\text { days (range) }\end{array}$ & $2(0-19)$ \\
\hline $\begin{array}{l}\text { Median duration of ICU stay in days } \\
\text { (range) }\end{array}$ & $6(1-31)$ \\
\hline $\begin{array}{l}\text { Median duration of hospital stay in days } \\
\text { (range) }\end{array}$ & $13(1-76)$ \\
\hline $\begin{array}{l}\text { Median age at second-stage surgery in } \\
\text { months (range) }\end{array}$ & $15.5(5-34)$ \\
\hline
\end{tabular}

A sternotomy was the most common approach for the surgery $(n=45 ; 90 \%)$. A total of 16 patients (32\%) required cardiopulmonary bypass during the shunt procedure due to haemodynamic instability or for other concomitant procedures. The innominate or subclavian artery was used as the proximal arterial connection in 35 cases (70\%). The median shunt size was $4 \mathrm{~mm}$ (range: $3-5 \mathrm{~mm}$ ), with a mean shunt-toweight ratio of 1.25 in neonates. The median duration of mechanical ventilation, length of stay in intensive care and total length of postoperative hospital stay was two days (range: 0-19 days), six days (range: 1-31 days) and 13 days (range: 1-76 days), respectively [Table 2]. Upon arrival to intensive care, all patients received an infusion of unfractionated heparin and were subsequently transitioned to low-dose aspirin once they could be fed enterally. After the primary shunt procedure, three patients (6\%) required ECMO support and six (12\%) had to undergo shunt revision during the same hospitalisation period.

A total of five patients died within 30 days of the index operation; subsequently, three of the remaining 45 patients died after discharge but before the second- 
Table 3: Outcomes according to diagnosis among infants and children with cyanotic congenital heart disease undergoing modified Blalock-Taussig shunt procedures in Oman $(\mathrm{N}=50)$

\begin{tabular}{|c|c|c|c|}
\hline \multirow[t]{2}{*}{ Variable } & \multicolumn{2}{|c|}{ Type of diagnosis, $\mathbf{n}(\%)$} & \multirow[t]{2}{*}{$P$ value } \\
\hline & Single ventricle $(n=25)$ & Biventricular $(n=25)$ & \\
\hline Median age in days at time of surgery (IQR) & $13(4-50)$ & 74 (15-107) & 0.020 \\
\hline Median weight in $\mathrm{kg}$ at time of surgery (IQR) & $3.1(2.6-3.6)$ & 3.4 $(2.9-5.2)$ & 0.271 \\
\hline Early mortality* & $4(16)$ & $1(4)$ & 0.048 \\
\hline Inter-stage mortality $^{\dagger}$ & $3(12)$ & $0(0)$ & \\
\hline Median age at second-stage surgery in months (IQR) & $12(6.8-14)$ & $22(16-24)$ & 0.019 \\
\hline Reintervention during initial hospitalisation $^{\ddagger}$ & $2(8)$ & $4(16)$ & 0.049 \\
\hline Reintervention during the interval period ${ }^{\S}$ & $2(8)$ & $9(36)$ & \\
\hline
\end{tabular}

$I Q R=$ interquartile range.

*Defined as mortality occurring within 30 days of the index operation. ${ }^{\dagger}$ Defined as mortality occurring between 30 days after the index operation and the next surgical stage. ${ }^{7}$ Surgical shunt revision. "Surgical shunt revision or catheter intervention.
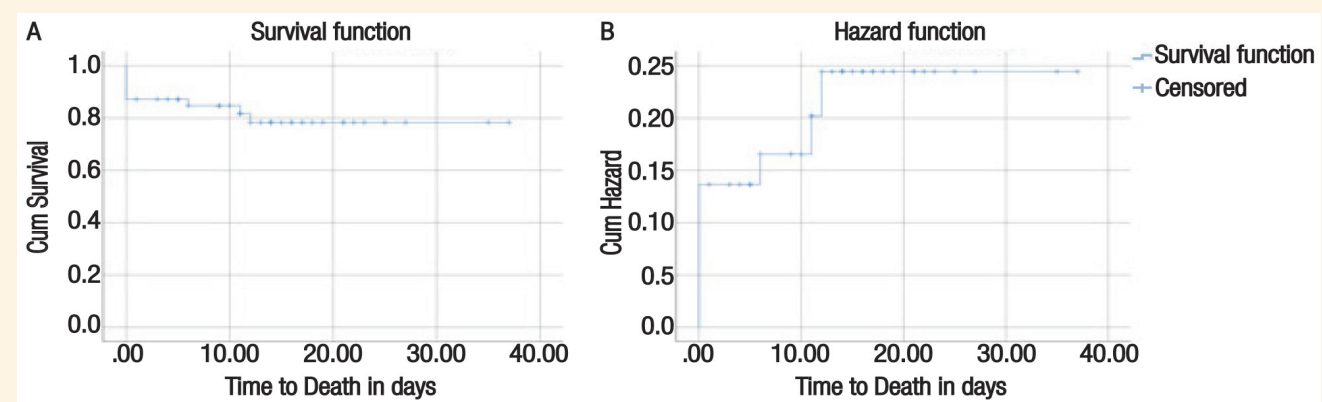

Figure 1: Kaplan-Meier curves showing (A) overall survival and (B) hazard of death after index surgery among infants and children with cyanotic congenital heart disease undergoing modified Blalock-Taussig shunt procedures in Oman $(\mathrm{N}=50)$.

stage surgery, resulting in early mortality and interstage mortality rates of $10 \%$ and $6.7 \%$, respectively. Of the five early mortalities, four (80\%) had single ventricle defects and one (20\%) had biventricular defects. The biventricular patient died due to myocardial dysfunction and low cardiac output syndrome on the sixth postoperative day. Among the four early mortalities in the single ventricle group, two (50\%) died due to myocardial dysfunction, one (25\%) due to septic shock and one (25\%) due to preoperative hypoxic-ischaemic encephalopathy and cardiac arrest during an attempt at ductal stenting. All three patients who died during the inter-stage period had single ventricle defects; of these one (33.3\%) died due to a chest infection and sepsis, while cause of death could not be determined in the other two patients $(66.7 \%)$ as they died at home.

During the inter-stage period, in addition to the three patients (6.7\%) who died, one patient (2.2\%) was labelled as not suitable for further surgeries and three patients (6.7\%) were lost to follow-up. The median interval before the second stage of surgery was 15.5 months (range: 5.0-34.0 months). Overall, 11 patients $(24.4 \%)$ who survived $>30$ days from the index operation required reintervention in the form of either surgical shunt revision $(n=6 ; 54.5 \%)$ or catheter interventions $(n=5 ; 45.5 \%)$. Most of these interventions were performed for patients with biventricular defects ( $n=9 ; 81.8 \%)$ and those with an underlying diagnosis of pulmonary atresia and VSD $(n=8 ; 72.7 \%)$. Differences in baseline variables and outcomes between the single ventricle and biventricular groups are shown in Table 3.

The majority of in-hospital deaths occurred within the first 10 days of surgery [Figure 1]. According to the univariate analysis, preoperative mechanical ventilation $(\mathrm{OR}=3.00,95 \% \mathrm{CI}: 1.98-4.76 ; P=0.007)$ and intraoperative cardiopulmonary bypass $(\mathrm{OR}=4.09$, 95\% CI: $2.44-6.85 ; P=0.002$ ) were the only statistically significant risk factors for in-hospital mortality. While other factors such as prematurity and underlying genetic conditions showed an increased association with in-hospital mortality, these differences were not statistically significant [Table 4]. 
In the current study, preoperative mechanical ventilation and intraoperative cardiopulmonary bypass were the only statistically significant risk factors for early mortality. Preoperative mechanical ventilation is a known predictor of adverse outcomes following paediatric cardiac surgery. ${ }^{17}$ In an analysis of 25,476 paediatric congenital heart surgeries, Jacobs et al. found that discharge mortality was significantly higher in patients who were mechanically ventilated preoperatively compared to overall mortality for neonates (15.1\% versus $9.88 \%)$, infants (11.5\% versus $2.91 \%)$ and children $(14.4 \%$ versus $0.92 \% ; P<0.001) .{ }^{18}$ Similar observations have been described post-mBT shunt surgery. ${ }^{10,14}$ On the whole, the need for preoperative mechanical ventilation reflects the precarious condition of these infants, which may explain the greater occurrence of adverse outcomes following surgery in such cases. It is also plausible that mechanical ventilation itself contributes to poor outcomes by altering the systemic-to-pulmonary blood flow ratio and increasing the need for sedation and neuromuscular blockade and the risk of pulmonary complications. Therefore, it is advisable to avoid elective intubation in this high-risk population, if possible. ${ }^{19,20}$

Moreover, performing a cardiopulmonary bypass during an $\mathrm{mBT}$ shunt procedure has frequently been associated with mortality, particularly among single ventricle patients. ${ }^{7,15}$ In this context, a cardiopulmonary bypass is generally performed due to preoperative haemodynamic instability or the need for concomitant cardiac surgery. There are several possible explanations for the association between cardiopulmonary bypass and adverse outcomes following $\mathrm{mBT}$ shunt procedures including activation of the inflammatory and coagulation cascades, alterations in pulmonary compliance and myocardial dysfunction and the decrease in diastolic pressure. ${ }^{7,15}$ In addition, previous studies have reported other predictors of mortality following $\mathrm{mBT}$ shunt procedures among paediatric CCHD cases such as low birth weight, underlying genetic syndromes, duct dependency and higher mBT shunt size-to-weight

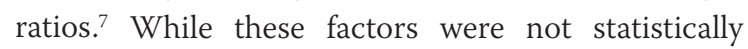
significant predictors of mortality in the present study, it is possible that the small sample size precluded further analysis.

In the immediate postoperative period following mBT shunt procedures, two predominant reasons for increased early morbidity and mortality include the occurrence of shunt blockade (due to kinking or thrombosis) and pulmonary overcirculation (also known as over-shunting). ${ }^{21}$ In the current study, $12 \%$ of patients required surgical shunt revision due to shunt blockade during the same hospital admission period, of which one-third later died. In contrast, pulmonary overcirculation (i.e. maintaining $\mathrm{SpO}_{2}$ at $>85 \%$ ) was not a significant risk factor for early mortality. This probably reflects an underestimation of the prevalence of this factor, given that the majority of in-hospital deaths were due to myocardial dysfunction and low cardiac output. Over-shunting is one of the major causes of ventricular dysfunction and low cardiac output syndrome after mBT shunt procedures. ${ }^{21}$

Palliative $\mathrm{mBT}$ shunt procedures lead to unstable circulation, with patients at high risk of death even after being discharged from hospital. Previous research indicates that the rate of inter-stage mortality after $\mathrm{mBT}$ shunt surgeries varies from $3-11 \% .^{9}$ In the present study, the inter-stage mortality rate was $6.7 \%$; this finding is in line with other published research, despite being calculated over a longer period of time. ${ }^{11}$ During the interval period, patients with $\mathrm{mBT}$ shunts are at an increased risk of acute adverse events caused by alterations to the systemic-to-pulmonary blood flow or due to acute shunt thrombosis, especially during periods of concomitant illness (e.g. diarrhoea or sepsis). Longer interval periods can also render the shunt inadequate due to neointimal proliferation or somatic growth, mandating reintervention. ${ }^{22}$

Cardiac catheterisation using a ductal or right ventricle outflow tract (RVOT) stent has been proposed as an alternative to an $\mathrm{mBT}$ shunt. ${ }^{23}$ Comparative research has indicated that this alternative strategy is not inferior to $\mathrm{mBT}$ shunts in terms of clinical outcomes and is superior in terms of other variables like hospital mortality. ${ }^{23-25}$ However, a sizeable number of cases in which attempts at ductal/RVOT stenting fail have been found to eventually require $\mathrm{mBT}$ shunts. ${ }^{23}$ While this subgroup of patients were observed to have a higher risk of death in the current study, the small study population precluded further analysis. As such, further research to compare outcomes between ductal stenting and $\mathrm{mBT}$ shunt procedures in a local setting might be helpful to guide patient selection.

The overall rate of surgical reintervention in the current study was $24 \%$. While this is similar to the rate reported by Bentham et al., it remains unarguably high. ${ }^{24}$ Moreover, half of these interventions took place prior to hospital discharge. O'Connor et al. reported that $9.7 \%$ of 207 patients required reintervention before discharge, whereas Do et al. observed the rate of in-hospital shunt failure requiring reintervention to be $7.3 \%$ among 9,172 at-risk infants. ${ }^{26,27}$ Prevention of early shunt failure and reintervention is very important as these events entail considerable mortality and morbidity. ${ }^{26,27}$

Reasons for the high rate of reintervention in the current cohort are not entirely clear and require further evaluation; however, it is worth mentioning 
that most reinterventions were performed for biventricular patients with underlying diagnoses of pulmonary atresia and VSD, especially during the interval period. This is understandable considering the complex nature of this lesion, with many surgeons preferring to employ a staged approach with regards to the initial placement of the mBT shunt to allow for the growth of the pulmonary arteries. ${ }^{28,29}$ As pulmonary atresia and VSD was the most common underlying diagnosis in the biventricular group, this could also possibly explain the longer interval period before the second-stage surgery among these patients.

Worldwide, outcomes following mBT shunt procedures are still poor compared to other types of congenital heart surgery. ${ }^{5,6,13}$ However, there nevertheless remains room to improve outcomes of this surgery among infants in Oman. Suggestions to decrease early mortality include improved patient selection with regards to the decision for surgical intervention compared to interventional cardiac catheterisation, the selection of appropriate shunt sizes, optimum anticoagulation to prevent shunt thrombosis and standardised postoperative management. ${ }^{30}$ Similarly, shorter interval periods, pre-emptive patient management during periods of concomitant illness and greater awareness of risk factors among community healthcare professionals and parents may serve as strategies to improve survival after discharge.

This study was subject to certain limitations. As the study was conducted at a single centre, utilised a retrospective design, involved non-standardised procedures and included a comparably small number of patients, it may have been affected by bias. Thus, the results need to be interpreted in the background of institutional practices and the specific study population. Notwithstanding these limitations, the findings of this study contribute to knowledge regarding the outcomes of palliative $\mathrm{mBT}$ shunt procedures in infants with CCHD in Oman. Moreover, these results may serve as a platform for targeted strategies to improve outcomes in this setting.

\section{Conclusion}

In the current study, $\mathrm{mBT}$ shunt procedures were found to carry an extremely high risk of mortality and reintervention in the treatment of CCHD in a paediatric population. These findings reflect those reported in the existing global literature. In particular, preoperative mechanical ventilation and cardiopulmonary bypass represented significant risk factors for early mortality. Further studies are needed to compare outcomes between $\mathrm{mBT}$ shunt procedures and cardiac catheter interventions in order to guide patient selection in this setting.

\section{ACKNOWLEDGMENT}

Authors would like to thank Dr. Hamood Al Kindi BSc,MSc,MD,FRCSC, Consultant Pediatric cardiac Surgery, National Heart Center, Royal Hospital and Sultan Qaboos University Hospital, Muscat, Sultanate of Oman; for valuable suggestions in manuscript writing.

\section{CONFLICT OF INTEREST}

The authors declare no conflicts of interest.

\section{FUNDING}

No funding was received for this study.

\section{AUTHORS' CONTRIBUTION}

SS and KSM conceived and designed the study and drafted the manuscript. SS, KSM and OD collected the data. AHR performed the statistical analysis and interpreted the results. All authors approved the final version of the manuscript.

\section{References}

1. Subramanyan R, Joy J, Venugopalan P, Sapru A, al Khusaiby SM. Incidence and spectrum of congenital heart disease in Oman. Ann Trop Paediatr 2000; 20:337-41. https://doi.org/10.1080/02 724936.2000 .11748155

2. Yee L. Cardiac emergencies in the first year of life. Emerg Med Clin North Am 2007; 25:981-1008. https://doi.org/10.1016/j. emc.2007.08.001.

3. Kiran U, Aggarwal S, Choudhary A, Uma B, Kapoor PM. The Blalock and Taussig shunt revisited. Ann Card Anaesth 2017; 20:323-30. https://doi.org/10.4103/aca.ACA_80_17.

4. Santro T, d'Udekem Y, Zannino D, Hobbes B, Konstantinov IE, Brizard C, et al. Determinants of acute events leading to mortality after shunt procedure in univentricular palliation. J Thorac Cardiovasc Surg 2019; 158:1144-53.e6. https://doi. org/10.1016/j.jtcvs.2019.03.126

5. Dorobantu DM, Pandey R, Sharabiani MT, Mahani AS, Angelini GD, Martin RP, et al. Indications and results of systemic to pulmonary shunts: Results from a national database. Eur J Cardiothorac Surg 2016; 49:1553-63. https://doi.org/10.1093/ ejcts/ezv435

6. Bove $\mathrm{T}$, Vandekerckhove $\mathrm{K}$, Panzer J, De Groote $\mathrm{K}$, De Wolf D, François K. Disease-specific outcome analysis of palliation with the modified Blalock-Taussig shunt. World J Pediatr Congenit Heart Surg 2015; 6:67-74. https://doi. org/10.1177/2150135114558690.

7. Alsoufi B, Gillespie S, Mori M, Clabby M, Kanter K, Kogon B. Factors affecting death and progression towards next stage following modified Blalock-Taussig shunt in neonates. Eur J Cardiothorac Surg 2016; 50:169-77. https://doi.org/10.1093/ ejcts/ezw017. 
8. Dirks V, Prêtre R, Knirsch W, Buechel ER, Seifert B, Schweiger M, et al. Modified Blalock Taussig shunt: A not-so-simple palliative procedure. Eur J Cardiothorac Surg 2013; 44:1096-102. https:// doi.org/10.1093/ejcts/ezt172.

9. Hobbes B, d'Udekem Y, Zannino D, Konstantinov IE, Brizard C, Brink J. Determinants of adverse outcomes after systemic-topulmonary shunts in biventricular circulation. Ann Thorac Surg 2017; 104:1365-70. https://doi.org/10.1016/j.athoracsur.2 017.06.043.

10. Petrucci O, O'Brien SM, Jacobs ML, Jacobs JP, Manning PB, Eghtesady P. Risk factors for mortality and morbidity after the neonatal Blalock-Taussig shunt procedure. Ann Thorac Surg 2011; 92:642-52. https://doi.org/10.1016/j.athoracsur.2011.02.030.

11. Sasikumar N, Hermuzi A, Fan CP, Lee KJ, Chaturvedi R, Hickey E, et al. Outcomes of Blalock-Taussig shunts in current era: A single center experience. Congenit Heart Dis 2017; 12:808-14. https://doi.org/10.1111/chd.12516.

12. Vitanova K, Leopold C, von Ohain JP, Wolf C, Beran E, Lange R, et al. Reasons for failure of systemic-to-pulmonary artery shunts in neonates. Thorac Cardiovasc Surg 2019; 67:2-7. https://doi.org/10.1055/s-0037-1621706.

13. Brown KL, Crowe S, Franklin R, Mclean A, Cunningham D, Barron D, et al. Trends in 30-day mortality rate and case mix for paediatric cardiac surgery in the UK between 2000 and 2010. Open Heart 2015; 2:e000157. https://doi.org/10.1136/ openhrt-2014-000157.

14. Mohammadi S, Benhameid O, Campbell A, Potts J, Joza J, Al-Habib $\mathrm{H}$, et al. Could we still improve early and interim outcome after prosthetic systemic-pulmonary shunt? A risk factors analysis. Eur J Cardiothorac Surg 2008; 34:545-9. https://doi.org/10.1016/j.ejcts.2008.06.001

15. McKenzie ED, Khan MS, Samayoa AX, Vener DS, Ishak YM, Santos AB, et al. The Blalock-Taussig shunt revisited: A contemporary experience. J Am Coll Surg 2013; 216:699-706. https:// doi.org/10.1016/j.jamcollsurg.2012.12.027.

16. Gewillig M. The Fontan circulation. Heart 2005; 91:839-46. https://doi.org/10.1136/hrt.2004.051789.

17. Ciociola EC, Kumar KR, Zimmerman KO, Thompson EJ, Harward M, Sullivan LN, et al. Association between preoperative respiratory support and outcomes in paediatric cardiac surgery. Cardiol Young 2020; 30:66-73. https://doi.org/10.1017/ S1047951119002786

18. Jacobs JP, O'Brien SM, Pasquali SK, Kim S, Gaynor JW, Tchervenkov CI, et al. The importance of patient-specific preoperative factors: An analysis of the Society of Thoracic Surgeons congenital heart surgery database. Ann Thorac Surg 2014; 98:1653-9. https://doi.org/10.1016/j.athoracsur.2014.07.029.

19. Guzzetta NA, Foster GS, Mruthinti N, Kilgore PD, Miller BE, Kanter KR. In-hospital shunt occlusion in infants undergoing a modified Blalock-Taussig shunt. Ann Thorac Surg 2013; 96:176-82. https://doi.org/10.1016/j.athoracsur.2013.03.026.

20. Meckler GD, Lowe C. To intubate or not to intubate? Transporting infants on prostaglandin E1. Pediatrics 2009; 123:e25-30. https://doi.org/10.1542/peds.2008-0641.
21. Soo KW, Brink J, d'Udekem Y, Butt W, Namachivayam SP. Major adverse events following over-shunting are associated with worse outcomes than major adverse events after a blocked systemic-to-pulmonary artery shunt procedure. Pediatr Crit Care Med 2018; 19:854-60. https://doi.org/10.1097/PCC.00000 00000001659.

22. Marino BS, Tabbutt S, MacLaren G, Hazinski MF, Adatia I, Atkins D, et al. Cardiopulmonary resuscitation in infants and children with cardiac disease: A scientific statement from the American Heart Association. Circulation 2018; 137:e691-782. https://doi.org/10.1161/CIR.0000000000000524.

23. Benson L, Van Arsdell G. Comparisons between ductal stenting and Blalock-Taussig shunts for infants with ductal-dependent pulmonary circulation. Circulation 2018; 137:602-4. https:// doi.org/10.1161/CIRCULATIONAHA.117.031998.

24. Bentham JR, Zava NK, Harrison WJ, Shauq A, Kalantre A, Derrick G, et al. Duct stenting versus modified Blalock-Taussig shunt in neonates with duct-dependent pulmonary blood flow: Associations with clinical outcomes in a multicenter national study. Circulation 2018; 137:581-8. https://doi.org/10.1161/ CIRCULATIONAHA.117.028972.

25. Glatz AC, Petit CJ, Goldstein BH, Kelleman MS, McCracken CE, McDonnell A, et al. Comparison between patent ductus arteriosus stent and modified Blalock-Taussig shunt as palliation for infants with ductal-dependent pulmonary blood flow: Insights From the Congenital Catheterization Research Collaborative. Circulation 2018; 137:589-601. https://doi.org/10.1161/CIRCU LATIONAHA.117.029987.

26. O'Connor MJ, Ravishankar C, Ballweg JA, Gillespie MJ, Gaynor JW, Tabbutt S, et al. Early systemic-to-pulmonary artery shunt intervention in neonates with congenital heart disease. J Thorac Cardiovasc Surg 2011; 142:106-12. https://doi.org/10.1016/j. jtcvs.2010.10.033.

27. Do N, Hill KD, Wallace AS, Vricella L, Cameron D, Quintessenza J, et al. Shunt failure-risk factors and outcomes: An analysis of the Society of Thoracic Surgeons congenital heart surgery database. Ann Thorac Surg 2018; 105:857-64. https://doi.org/10.1016/j. athoracsur.2017.06.028

28. Lertsakulpiriya K, Vijarnsorn C, Chanthong P, Chungsomprasong P, Kanjanauthai S, Durongpisitkul K, et al. Current era outcomes of pulmonary atresia with ventricular septal defect: A single center cohort in Thailand. Sci Rep 2020; 10:5165. https://doi. org/10.1038/s41598-020-61879-2.

29. Van Puyvelde J, Meyns B, Rega F. Pulmonary atresia and a ventricular septal defect: About size and strategy. Eur J Cardiothorac Surg 2016; 49:1419-20. https://doi.org/10.1093/ ejcts/ezv443.

30. Ismail SR, Almazmi MM, Khokhar R, AlMadani W, Hadadi A, Hijazi $\mathrm{O}$, et al. Effects of protocol-based management on the post-operative outcome after systemic to pulmonary shunt. Egypt Heart J 2018; 70:271-8. https://doi.org/10.1016/j.ehj.20 18.09.007. 